\title{
APPENDIX
}

\section{Texts in Transliteration}

\section{Chapter 2. Poets Inside and Outside the Epic}

\author{
Text 2.1 \\ Shaykh Ṭāhā Abū Zayd, tape 87-I I s/6 (6/I 3/87) \\ laffèt bilād is-sind-I wi-l-hind-I wi-l-yaman \\ ruḥt $^{\text {an }}$ bilād ${ }^{\text {an }}$ tirkab il-afyāl \\ mā laqēt-I afras mi-z-zanātī bi-himmatuh \\ wa-la jwad min zēd il-cajāj-I rijāl \\ wa-la jwad min hazā wa-hazā illā nabīyana \\ il-hāshimīi li-l-mưgūzīn-I msāl
}

Text 2.2

Shaykh Biyalì Abū Fahmī, tape 87-OI2/I2 (2/I4/87)

fa-qāl luh "yā shācir jamīl»" q'āl luh "nacam yā bū calī" qāl luh "durt 'alā nās ma'dūda, wa-akābir 'arab mansūbahaddish 'ațāk il-cațā wi-jabarak qaddī anā wi-'arabī?»"

ish-shācir adūb. ish-shācir adūb, mā kull-I shāeir yimsik ir-rabāba yibq’āa

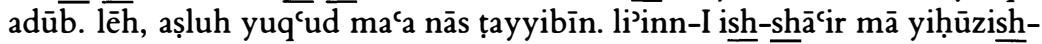
I qillit il-adab abadan. biyimshī calā r-rabāba. . . . añ̄ mā bamgadsh-I fi

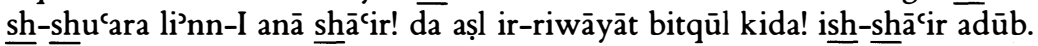




\section{I4 Appendix}

wi-lawlā adūb, mā kānsh-I yimsik ir-rabāba wi-yuq'ud wusț nās țayyibīn. iz-zayy yibq’à shā̄ir il-mulūk wi-l-'arab wi-yibq'ā qalīl il-adab?! yibq’ā mu’addab. wi-l-qa ${ }^{c}$ da barḍu yismac ish-shā'ir, yibq'ā barḍu fī ghāyit iliḥtirām. fa-innī. . . .

bașṣ-I-luh ḥasan kida wi-qāl luh, "yā shāecir jamīl"

qāl luh "nacam"

qāl luh "inta durt 'alā nās macdūda, wa-akābir carab mansūbahaddish 'ațāk 'ațā wi-jabarak qaddī anā wi-'arabīi?"

bașș-I-luh ish-shācir jamīl.

ihna qulnā ish-shāeir adūb, ya'nī mu’addab.

qāl luh "yā bū calī, inta ka-bahr in-nīl, wi-l-ajāwīd illī ihna binliff-I calēhum il-carab, ka-buhūr in-nìl. fa-l-baḥr, fīh miyā wa-zalāl, fa-l-baḥr mā yitfaḍụalsh 'an ba'ḍ.

yiqașșarsh wi-yiskut ḥasan baqā . . . ish-shā ${ }^{c}$ ir 'ațāh ijāba hịilwa ma ${ }^{` a}$ l-caql ik-kwayyis.

Text 2.3

Shaykh Biyalī Abū Fahmī, tape 87-009/I (2/I3/87)

'andak yā ḥanḍal tamanīn șabiyya wi-kull-I șabiyya abhar min q'amar shacbān

yā ra'sahā ras il-yamāma șughayyara

wi-sh-sha'r sābil calā l-Qumṣān

wi-l-idirāa zayy is-suyūf il-mifạ̣dạ̣a

wi-f $\overline{1}$ yad-I cāyid nāzil il-mīdān

wi-l-khadd țabaq' il-ward gall al-lāzī șanac

șanacit muhaymin wāḥid ${ }^{\text {an }}$ dayyān

khațarum 'alā il-baḥr wi-zaqzaq is-samak

in shāfihum ish-shēkh tāarit wilāytuh

in shāfhum il-c̄ālim nasā l-Qur’ān

in shāfhum il-qammāsh ('alēhi il-cawaḍ!)

yiḥsib iș-șūf dabalān

q'ācidīn f'ì dīwān il-cizz yā malik hanḍal

allāh yiَīnak dīwān mushayyid dīwān mushayyid

yā hạậrit il-sul[țān] . . . cidād hāyil q’aw[ī]

fīh q'ulal bannūr hịilwa li-l-'ațshān

hanafiyyāt fiḍḍa, hanafiyyāt fiḍḍa

tinazzil nahr-I zalāl

q'ācidīn fī dīwānak yallāh yiṣliḥ hạālak

hạanḍal yā sulțān

naẓar il-malik hanḍal l-abū zēd wi-q’āl luh

ahlan wi-sahlan yā shāeir il-curbān

lìk 'andinā fiḍḍa līk candinā dahab

lìk 'andinā khēl wayya gimāl

il-arḍ arḍak yā shācir il-carab

il-arḍ arḍak wi-l-bilād dī blādak

wi-ḥna yā sīd wi-līk 'abīd khuddām 
Spoken:

qāl abū zēd mutshakkirīn yā malik hanạal

tiddīnī faḍda li-mīn aw dahab li-mīn

Sung:

'ațāyā min dōl șabiyya awșāfhā rawhiyya

tikhdim jaddak ish-shācir rāgil kibīr bațlān

radda lahu hanḍal $\overline{l-a} \overline{\text { ù }}$ zèd wi-q’āl luh

khud rayya bint abū zēd yā shācir il-carab

Spoken aside:

[q'ulnā abū zēd itjawwiz butēma ukht-I diyāb, fōq 'alya iz-ziḥlāniyya illī kānit min qadīm khallif minhā talāta șubyān wa-unsa: khallif ṣabra, wimikhēmar, wi-cakrama, wi-rayya]

Sung:

itf aḍ̣al rayya bint abū zēd minnī qabālak

wi-ticīsh macāk yā 'amīr maḍā l-azmān

khud rayya bint abū zēd minnī qabālak

wi-ti'îsh macāk yā 'amīr wallāh maḍā l-azmān

yā salām lammā tākhud rayya yā shāeir il-carab

yirūh ish-shēb wi-l-kibar tirjac shubbān zayy zamān

abū zēd 'ațā $\bar{r}$-rimūz li-rayya itqad̄imit . . .

hanḍal rāh masak rayya min dirāeēhā

wi-q'āl khud dī lìk yā shā'ir il-‘arab

wi-t'`ish mā̄àk yā 'amīr bi-kull-I ’āmān

wi-t'⿳亠口冋h ma`āk yā 'amīr wallāh bi-kull-I ’amān

rayya bint abū zēd jāt sabbit il-ḥēla

22

q'ālit luh ukhraṣ yā gabān

lā kunt-I walā kān yā hạậal yā khawwān

dā nā bint abū zēd shēkh il-carab

bint-I shēkh il-carab abū zēd

tiddīnī li-shāèir bi-r-rabāba yiliff ca l-curbān?

dā 'anā bint ẩū zēd shēkh il-carab

abū l-buṭūla min zamā̄n

ya 'lam bi-zālik abūyā abū zēd il-hilālī

la-yikhallī dammak ca l-arḍ țūfān

\section{Chapter 4. The Interplay of Genres}

Text 4.12. Example of Hitat Baladī

Shaykh 'Abd al-Wahhāb Ghāzī, tape 87-044 (3/i s/87)

mīn maqșuduh l-janna yiṣallī calā n-nabī

nabì 'arabī luh hạaram masbūt

wi-r-rizq min 'and illāh bikhūt wi-bikhūt 
wa-fīh man yactịh

aywa jūda maca karam

wa-fīh mīn yưțīh bukhl-I lammā yimūt

wa-fīh mīn yưțīh janāyin muzaghrafa

wi-fīhā manje wi-fīhā kummitre

fīhā 'ēnab fīhā balah

fīhā rummān fawākih yā khūyā 'aẓīma

ir-rizq min cind-I rabbunā bikhūt wi-bikhūt

wi-fīh minn yucțîhi shagara sanț-I

wallāh yā 'ēnī aw dakar tūt

wa-fīhi mīn yu'țīhi qufțān wi-jūkha

wa-fīh min yuctị̂h khalaq za'būt

wa-fīhi mīn yu'țīh walad

wi-zākī mu’addab walad mitrabbì

tīgī sīrt il-walad yirḍā abūh fī j-jalsa

yā khūyā raqabtuh țawīla ay qā̄id mabsūṭ

ādī l-walad țālic li-khāluh

khāl il-walad rāgil min uṣūl il-buyūt

wa-fīh min yưțīh walad wi-khāyib wi-hāyif

aywa yā 'ēnī qabīh sharmūṭ

yigīb li-abūh il-mashākil wi-l-jarāyir

wi-d-dakākīn wi-l-qahāwī wi-l-ghētān

wi-l-ōtōbīsāt wi-l-qațr ayy wi-kull-I buyūt

'alashān abūhu rāgil masmūc wi-țayyib yîrūhū yiruddū calā abūh f $\overline{1}$ filūs wi-mi`ādāt

yā khūyā walad țālic hāyif li-khāluh

așl-I khāluh rājil halfūt

wa-fīh mīn yưțīh jawwāza hasīna jamīla

hilwa qawī yā khūyā jamīla hasīina

așīla min uṣūl il-buyūt

wi-l-wajh-I abyad w-il-khadd-I yilmac

yishbah il-yāQūt

'anduh dūyūf māyil luh

kull-I iṭ-țalabāt tījī li-ḍ-ḍuyūf wi-zawjihā qācid

min dūn mā yush'ur walā yaclim

wa-lā yiqūl yā bintī hātī walā w-iddī

iṭ-țalabāt tìjī li-ḍ-ḍuyūf

wi-zawjihā qā̄id wayyā ḍ-ḍuyūf mabsūṭ

ḥadqiyāt wa-ruzziyāt

waḥda așīla jamīla hịilwa qawī

min uṣūl il-buyūt zawjihā qā̄id maca ḍ-ḍyūf mabsūṭ

yinādī cā ț-țalab-nacam wi-hạạị

na'am wi-hāḍir na'am wi-hāạdir

wi-s-sinn-I yiḍhak min wajhā abyaḍ yishbah il-yāQūt

zawjihā in 'āsh michā tamānīn sana tisa'īn sana

kammil il-miya 
(wi-l-a'mār bi-yad illāh)

hāyiণish wi-yimūt fī farḥ̂-I baq'ā mabsūṭ

wa-fīh mīn yưțīh jawwāza yā khūyā

rabbunā lā yikassibhā wa-lā yikassib illī gābūhā

wi-llī khallifūhā wi-llī shārū bihā

jawwāza baqā il-yōm wì-balwa musayyaḥa

cawīla bakhīla cawìla bakhīla

min acwal buyūt lihā l-zōr tishbih il-qarmūṭ

allāhu akbar allāhu akbar

ammā ḍ-ḍēf yirūḥ yam-I dārhum

tiqūm yā khūyā sahịiba n-nabbūt

anā jāyy li-camm-I fulān

tiqūl cand id-daktōr yā akh

biyimūt biyimūt biyimūt biyimūt

dā-nā sāyil calēh wa-nā jāyy 'alā s-salamōniyya

kidā mi sh-sharq aw min calā l-miqāwila min baḥrī

min sikka il-mahațta bitāenā il-qațr

dā sana hịlwa qawī

wi-l-quṭn-I jāwib itnāshir qințār is-sana

dì fī t-ta'mīnāt wa-fī $\bar{l}$-ișlāh

wi-fī l-mullāk dā bi-tis'a wi-nușș-I aw 'ashara kidā

wi-l-ittimān wi-z-zirāca hịilwa wi-saddū l-jamaciyya

wa-baqēt mabsūṭ

yārēt yā būyy qabl-I mā tijī bi-khamsa daqāyiq

il-carabiyya jāat khaduh hāyimūt hāyimūt

sāyil calēh wa-nā jāyy

min yam il-fazāciya ca l-gharb-I kidā

kafr is-siraḥna cind abū șubḥ camm il-ḥājj muhamammad

rāgil amīr ahl il-karam il-karam mabsūṭ

sā'il 'alēh cind mad mușțafã rāgil țayyib

wi-l-hạāj kāmil ayḍan

'ammī fūlān qālū dā s-sana ḥilwa qawī

il-mara tiqūl biyimūt biyimūt

yārēt yārēt yā khūyā biyimūt

mā hiya bint-I bukhalā!

ir-rāgil qāeid fī l-mandara

zayy bitācit aḥmad bakhātī

illī ihnnā hạàdritnā jālisīn fî̀hā

l-lēla dì li-jamc sa'̄ìd

in shā’ allāh jam'in khēr

bi-ṣ-ṣalā calā n-nabī muhammad

nūr in-nabī ayy milā t-tabūt

illī yikhāe calā sum cituh yiṭlac mi l-bāb il-qiblī

min ij-jiha ish-sharqiyya illī yam il-mashrūc da

wi-yitlaff-I wi-yiqābil iḍ-ḍiyūf

yā marḥaba alf-I malyōnī marḥaban yā marḥaba 
itfaḍḍalum tacālū tacālū

itfaḍḍalum naf aḍ ik-kanab wi-s-safīnjī wi-mukhaddāt

wi-takkāyāt wi-layyināt

il-ḥikāya il-ḥamdu li-llāh

baqat hịilwa fī kull id-dunyā

saf înjī yāmā takāyāt yāmā wi-mabānī hịilwa

ākhir riḍā l-ḥamdu li-llāh

qāl il-ḥamdu li-llāh

baqā aghnā in-nās illī yīَish mabsūṭ

wi-yuq'ud yihayyihum

wi-yirushsh 'alēhum shwayyit sagāyir

wi-shwayyit mashrūbiyāt wi-shwayyit hạāāwiyāt

wi-ba'cdēn lammā yihtād il-manhūba il-halība

bint il-mașāyib dī tiqūl èh:

yā dā l-cadā yā dā l-cadā

‘āwiz ēh?! luqma li-ḍ-ḍuyū dōl yakūlum

baqā lhum sācitēn qā̄idīn candinā

anā kunt-I hācid il-kashf in-nihārda

ammā lammā shuftuhum min il-bāb ish-sharqī

anā ruḥt-I bi-sur'ca barḍu biyi’amin 'alā kalāmhā

kalām il-manhūba tiqūl èh:

anā cind̄i ciyādit ik-kashf ya'nī biyi'āmin calā

kalāmhā barḍu 'alashā̄n yi îsh mabsūṭ

iḥnā wilādhum yā khūyā āh minnuh

cindī ciyād kashf in-nihārda

lakin lammā shūft iḍ-ḍuyūf āhum

iṣ-șiḥha baqat ḥilwa il-ḥamdu li-llāh qawī

hāt linā l-ghadā timḍī' baq'ā sācitēn mā adrī talāta

akl bi-l-cagal tirūh tijīb il-akl yā khūyā

wi-twaḍ̣ạa $u$ qudāmuh wa-tiḍrab bi-șōt qawī ēh

yā ddī l-khabar abyạ̣ yā tijīb lihum il-murr

barḍu caqarit calēhum, hāyaklū èh?

yisībū l-akl baqat janāza wi-illī yicūzū bi-llāh . . . aṣhāābum

așlihā bakhīla wi-bint-I bukhala min a $a^{c} w a l$ buyūt

yimashshū dụ-ḍiyūf wi-r-rāgil yā cēnī

calā ghēr khāṭiruh

bacdēn māhūsh mabsūt

yirjac yiqūl lihā

lēh kidā lēh, lēh kidā lēh

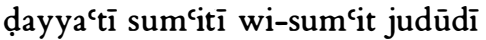

inn il-karīm lā yinḍām, il-karīm lā yinḍām

wa-n-nās dōl mưtādīn yigū cindinā

ayyām abāhātnā wi-judūdnā

wi-l-bēt dā maf tūh min zaman q'awī

tiqūl luh: mish shughulak uskut 
ya'nī inta fătih al-baḥ̂ī

uq'ud uq'ud sākit

wi-khēr rabbunā yāmā

wi-ḍ̂-ḍef qabl-I mā ya’tī ya’tī bi-rizquh qudāmuh

wi-tlamm-I wi-ndāra kidā

dā-nā țūl in-nihār adawwar calā daqīq fī d-dakākīn

ruht t-I li-abū sulēmān wi-li-ustāz jalāl

laqēt id-daqīq candihum mashhụụt

tayyib wi-hinā shwayyit 'ish ahom

uskut! mā huwa anā illī bakhabbiz

anā illì babațțit wi-diractī yitwagacnī

aq'ud mish ... . ù ${ }^{c} \bar{a} \bar{u} \bar{u}^{c} a ̀$ !

wi-kilma minhā

wi-kilma min zaw jihā timsik khināqa

tisharmaț il-zacbūṭ

[ya'n̄̄ tigīb ig-galabiyya mi-l-bidāya li-n-nihāya

innamā iz-zacbūṭ 'alashān il-Qāfiyāt]

tiqațțac iz-zacbūṭ tisharmaṭ iz-zacbūṭ

yā wiliyya färiqīnī rūhì dār ahlik

wallāh mā fărqak li-akūn candak lammā timūt

wa-mā kān in-nīl yigīnā fō misrā,

ammā kān in-nīl yijīnā $f \bar{i}$ misrā

wa-lā khēr fī nìl tijīnā $f \bar{i}$ tūt

yibq’ā iz-zarc'a 'addā cumruh baqā

bacd khamsa wi-talātīn yōm baqā tijī il-mayya

kull il-quṭn-I māt wi-rāḥ li-ḥāluh

wi-lammā kān in-nīl yijīnā fī misrā

lā khēr fī nīl tijīnā fī tūt

wa-mā kān il-fatta wi-l-'īsh

bi-ziyāda 'an il-kōsa

wa-lā khēr fī zād yijī mashhụụt

wi-llì mā yimūt ayy minēn-I yifüt

wi-r-rizq min cand-I rabbunā ayy bikhūt wi-bikhūt

wa-fīh mìn yu'țih jūda wa-karam

wa-fīh mīn yīish fī l-bukhl ayy wa-lammā yimūt

ayy wa-fīh min yư țīh 'umr-I kifayituh

wa-fīh mīn yu'țīh sana wi-yimūt

wi-r-rizq min cand-I il-karīm rabbunā

ayy bikhūt wi-bikhūt

wi-'afḍal-I min dā $\overline{1-Q} \bar{o}$

anā wa-intum jamī'an yā sāmicīn il-Qōl

șallum 'alā hạậrit in-nabī

nabì 'arabì wì-luh hạam masbūt 


\section{Chapter 5. The Sahra as Social Interaction}

Text 5.1. Audience Participation (Birth of Abu Zayd)

Shaykh Ṭāhā Abū Zayd, tape 87-IOI (6/I/87)

wa-kān șābih jim‘a șallum calā n-nabī,

[All: 'alēh iṣ-ṣalāt wi-s-salām]

wa-li-l-maẓlūm rabbī sāmic li-d-du`āh.

qālit lihā:

2

"yallāh anā wi-ntī ca l-baḥr-I fī l-faḍā, yallāh nirawwaq damminā fī faḍāh.

wa-tinẓurī l-māliḥ tilāqī l-cajāyib,

tilāqī l-cajāyib bi-arādt illāh.»

țalacum baqā l-itnēn wa-l-cabd-I sa`īde,

illā wa-țīr

[Voice: aywa!]

abyad min il-bu'd-I jā lahum,

dā țîr abyaḍ hịlw-I fī ru’yāh.

inhạțț-I wa-lā shāl iṭ-țīr fī l-khale,

kull iṭ-țiyūr aywa lìh tircāh.

qālit shamma "yā rabb yā fard-I yā șamad,

illāh ${ }^{\text {in }}$ tacālā lā ilāh ${ }^{a}$ siwāh.

[Voice: allāh]

tirzuqnī bi-wād anā misl-I iṭtțīr hāzì,

wi-yakūn hịin tikūn il-‘arab țāyicāh.»

tammit baqā l-țulbe yā-jāwīd wi-ț-țīr irtafac, wi-ț-țīr shāl āh wi-zād fī culāh.

illā wa-țīr asmar min il-bưdd-I jā lahum, 
[Voice: aywa!]

bishih fī ru’yāh.

[Voice: yā salām!]

yuf rud gināḥuh 'alā ț-ṭiyūr,

kull-I man ḍarabuh bi-gināḥuh lā yishimm-I

'ashāh ...

[Side Two]

kull-I man ḍarabuh bi-gināḥuh lam yishimm-I

'ashāh

qālit-I Khaḍra:

[Voice: aywa]

samārak

"yā maḥlāk-I yādī iṭ-țîr wi-maḥlā

[Voice: allāh!]

zayy il-balaḥ ammā yị̂īb bi-riḍāh.

ayā rabb-I yā raḥmān-I yā fard-I yā șamad,

[Voice: allāh yif tah 'alēk!]

[Shaykh Tāhāa: allāh yikrimak!]

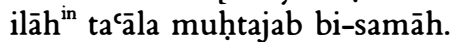

[Shaykh Ṭāhā: yidūm 'izzak, yidūm 'izzak 'alēnā!]

tirzuqnī bi-wād anā misl-I iț-țīr hāza,

wi-kull-I min ḍarabuh bi-sēfuh lam yashimm-I

I4 'ashāh."

[Voice: yā salām! dā abū zēd!]

țalabum il-isnēn:

qālit sa'īda "yā rabb tirzuqnī misl-I asyādī

mā-khafsh-I mīn kān fī l-karīm arḍāh."

dōl rawwaḥum yā ajāwīd șallum 'alā n-nabī,

I6

[All: calēh iṣ-ṣalāt wi-s-salām]

ayā bakht-I min țalab wa-l-karīm arḍ̄āh.

Qāl il-malik sarḥān li-rizq-I il-bațal,

"yā ibn-I 'ammī sma' kalāmī wi-l-mu'nā.

șālih ish-sharīfa rizq ayā țayyib il-carab, 
yā tikrimhā yā rizq yā tiwaddīhā li-ahlihā,

wi-l-carḍ-I zayy iz-zirc wi-l-carḍ-I ghālī,

wi-l-carḍ-I ghālī wi-l-carab carfāh."

[Voice: allāh!]

șāliḥhā yā ajāwīd wi-waddīhā li-ṣīwānuh, wa-arād il-karīm alā bi-l-hudā yā maḥlā.

fī hāzī l-lēla ḥamalū s-salāsa,

yā bakht-I min țalab wi-l-karīm arḍ̄h.

wafit shuhūrhā shamma l-așīla;

waḍa $\overline{\text { it }}$ ghulām yā ajāwīd Qalīin sifătuh, walad samīḥ il-wajh-I yā maḥlā.

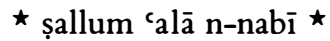

[All: 'alēhi ṣ-ṣalāt wi-s-salām]

[Shaykh Ṭāhā: allāhum yiṣallī calēh]

[Voice: yā salām . . . ismac . . . ]

[Shaykh Ṭāhā: allāh yikrimak! allāh yibārik

fïkum!]

Text 5.3. Suppression of Materials for Female Listeners

Shaykh Biyalī Abū Fahmī, tape 87-029 (2/25/87)

. . . qālit luh: mā-ntish fâtiḥ, yā Manșūr? qāl: intī tighannī wa-nā ghannī 'ubālik, in zidtī 'annī $\overline{\mathrm{f}} \overline{1} \mathrm{l}$ l-qōl, atjawwiz arba' niswān wi-tibqī intī awwil il-qāyma, wi-in zidt-I 'annik fī l-qōl tākhdī in-niswān wi-timashshī min hinā wi-iḥnā baț̣alnā il-ḥubb-I wa-l-ḥamdu li-llāh. qālit luh ij-jāzya: ifrash wa-nā aghațțī. qāl lihā: intī ghalațtī-ish-sharī́a illī rabbunā mihallilhā bìinn-I in-nisā' furrāsh ir-rijāl, li’in ir-rijāl mitfaḍdalīn 'alā n-nisā', wa-nnisā’ furrāsh ir-rijāl, ya‘n̄̄i illī yif rish mīn bi-l-kalām? qālhā: intī tif rishī bi-l-kalām wâ-nā aghațțī calēkī bi-l-kalām. fa-j-jāzya tifrish tiqūl ēh? cāshị in-nabì yazīdnā mi-ṣ-ṣalātu calēh:

Sung:

anī amdah muhammad națaQit luh l-ḥigāra

națaQit luh l-ḥigāra

[Tunes rabāb]

anī amdah muhammad naṭaqit luh l-ḥigāra yā rabbī nizūruh nistamtac bi-nūruh nistamta ${ }^{\complement}$ bi-nūruh wa-ninūl iz-ziyāra, wa-nnūl iz-ziyāra 
qālit bint-I sarḥān-ī qawāfi' wi-awzān-ī taww ish-shicr bān-ī wi-baqā lì fīh amāra

iftaḥ yā manșūr

iftāh bāb is-sūr nudkhulū bi-dastūr wi-nibīì̄ l-cițāra

iftah mā takhafsh-i

wa-law rìa laksh-î

il-hinna l-balakhshī

fī ìdēn il-cadārā

iftaḥ yā ḥabībī

yā miskan wa-țî̀i

hākhudak min nasībī

yā bawwāb naḍār, yā bawwāb naḍār

radd-I il-bawwāb manșūr ‘ā g-gāzya kida; wi-qāl ēh?

anā bābī mā ftahụush-ī

li-llī mā ba'rafüsh-ī

wa-ntum 'arab țumūsh-ī

fatḥ il-bāb līkum 'alā kh hasāra

yā bawwābī iftah bābak il-mișaffah

yā bawwābī iftah bābak il-miṣaffạ̣ wi-in dakhalu biyirbah

wi-biyibìc il-cițāra

ah mā tikūnsh-ī khāyif

ah mā tikūnsh-i khāyif

awarrīk il-wașāy $\overline{\text { if }}$

wi-nil`ab yā wișāla, nil`ab yā wișāla

il-bawwāb manșūr qāl lihā ēh:

mashshī yā șabiyy

balāsh manāhịyya

tigī li-l-bawwāb raziyya

wa-lā tiduqq fōq rāsuh ghāra 
224 Appendix

abadan mish fāth il-bāb

abadan mish făth il-bāb

wallāh bi-ḍ̆arb-I hirāb

min 'askar sakāra

rūhị yā ẓarî́a

rūḥi yā zarîifa

khūf ī min khalīfa

bi-īduh harba rahīfa

bitfūt min il-higāra

if taḥ yā manșūr

I 2

iftah bāb is-sūr

dastūrī bi-dastūr

yā wish il-khusāra

ayā bawwā̄ manșūr wishak wish il-khusāra

iftah wa-nā awarrīk

awșāf al-cadārā

(il-cadārā ya'nīi il-banāt)

iftaḥ wa-nā awarrīk

awṣāf al-'adārā

cindinā cālya il-cuqēliyya

I4

wi-cālya iz-ziḥlāniyya

wi-cindinā is-sitt-I wațfa iz-zughbiyya

cindinā is-sitt-I sāra

sacdiyya wi-r-rasmiyya

IS

sacdiyya wi-r-rasmiyya

wi-j-jāzya il-carabiyya

il-jāzya il-carabiyya

țama‘ān lihā l-idāra, țamacān lihā l-idāra

zaqq il-bāb wi-rāyị̣

I6

il-wujūh is-samāyih

șafí il-misk fäyih

min cālya wi-sāra

wi-l-bawwāb-I hām

khad il-muftāḥ wi-qām

khad il-muftāḥ wi-qām

fatah il-bāb jihāra 
il-bawwāb firish giyāsuh

wi-qalac madāsuh

wi-qalac madāsuh

wi-hijim ‘̄a l-cadāra

il-bawwāb firish giyāsuh

wi-qalac madāsuh

wi-salāmtuh wi-hall-I libāsuh

wi-nawwil cā l-khusāra, wi-nawwil cā l-khusāra

jā luh abū zēd il-asmar

20

rākib zayy-I cantar

fī-ìduh is-sēf il-abtar

darab manșūr il-acgar

khallā rāsuh tidacwar

zayy-I zirr-I khiyāra

wi-ādī fatḥ-I bāb-I tūnis

li-yahịa wi-mar`ī wi-yūnis

wi-ādì fatḥ-I bāb-I tūnis li-yahịa wi-yūnis

wi-yūnis qācid $\mathrm{f}^{\mathrm{i}} \mathrm{s}$-sign wi-sāmic il-cibāra

waqa` il-bawwāb manșūr

difinūh janb-I is-sūr

qilibū fōq dimāghuh

it-tamanin shukāra

șallum ‘alā n-nabī 
